\title{
El fenómeno social de las exposiciones temporales
}

\author{
Manuel Ramos Lizana \\ Asesor Técnico de Conservación e \\ Investigación \\ Museo de la Alhambra
}

\section{Resumen}

El presente artículo realiza una reflexión sobre el devenir histórico de las exposiciones temporales en la sociedad europea occidental para llegar así al momento presente, cuyas tendencias al respecto son también someramente evaluadas. Para ello se ha intentado escoger, especialmente, los ejemplos españoles o andaluces, en sintonía con el carácter monográfico de esta publicación.

\section{Palabras clave}

Exposiciones temporales / Exposiciones universales / Comunicación

\section{Introducción}

La exposición temporal forma parte inseparable de la cultura occidental a diferencia de otras culturas, tanto como los propios museos. Su arraigo y su papel social han sido tan importantes como los de aquellos. Pero, más antiguas, más versátiles y experimentales que las exposiciones permanentes han influido decisivamente en todo tiempo sobre éstos. Su ventaja (y su diferencia más sustancial respecto a los museos) consiste en su vinculación con el divertimento y lo festivo tanto como con el conocimiento, ganando así un espacio de exposición no sacralizado.

Pero histórica y socialmente las exposiciones temporales no han sido uniformes. Podemos decir que, de alguna manera, han existido dos corrientes paralelas que podemos resumir en la exposición popular y la exposición elitista. La primera pasa por el carnaval, la fiesta barroca, los arreglos de patios y cruces del 3 de mayo, el circo, el teatro, la barraca de feria con su desfile de atrocidades (siameses, tragasables, la mujer barbuda), las exposiciones universales, las exposiciones comerciales, los museos de cera, las campañas institucionales de los organismos internacionales, las ferias de muestras (incluyendo la propia BIMU, Bienal de Museología que se celebra en Madrid) o los parques temáticos. La segunda comienza en el gabinete y la galería aristocráticos, se abre socialmente con las academias despóticas, vuelve a abrirse con las vanguardias y sigue ampliando su proyección social a lo largo del siglo XX. Es la exposición artística que -no obstante- continúa siendo minoritaria y que "se defiende" en su posición destinada en buena medida a mantener la distancia social.

Efectivamente, la gran democratización europea que comienza tras la Segunda Guerra Mundial supone el encuentro paulatino entre la exposición artística y/o académica y la exposición popular. Se produce entonces una reacción lógica destinada a reponer la distancia social que se materializa, por ejemplo, en las exposiciones de arte contemporáneo, para cuyo disfrute sigue siendo imprescindible un conocimiento previo sólo asequible para aquellos que disfrutan de abundante tiempo libre. En realidad, hoy por hoy coexisten, como veremos, todo tipo de exposiciones, tanto aquellas en que se ha producido la unión del viejo ritual festivo con el ritual sacro, dando lugar a un nuevo ritual interclasista de consumo, como aquellas exclusivamente banales o rabiosamente elitistas.

\section{Evolución histórica de la exposición temporal}

\section{Los orígenes}

Cuando las ciudades dejaron de ser señoríos colectivos o núcleos de pocos habitantes, tal como habían sido en las postrimerías de la Edad Media, para con- 


\author{
Pero histórica y socialmente las exposiciones temporales no han \\ sido uniformes. Podemos decir que, de alguna manera, han \\ existido dos corrientes paralelas que podemos resumir en la \\ exposición popular y la exposición elitista
}

vertirse en auténticos centros urbanos con una considerable población, se extendieron y generalizaron determinadas costumbres festivas entre las clases populares. Entre ellas hemos de destacar el carnaval con todo lo que conlleva de mascarada, disfraz, juegos de escarnio, de exceso y desenfreno desatados bajo la excusa de la llegada de la Cuaresma. Eran los resabios de la cultura popular campesina.

Pero esta cultura popular campesina de la que sólo nos han llegado algunos testimonios tardíos y esporádicos, fue en buena medida arrinconada en favor de la cultura urbana y de élites que pertenecía a la Iglesia y el Estado. El resultado va a ser la fiesta barroca. Mediante ésta, al tiempo que se socializa a la nueva y crecida población urbana se la integra socialmente, mostrándose en su mayor esplendor el boato de las instituciones del poder, jerarquizadas en el riguroso protocolo procesional.

El precedente más remoto de las exposiciones temporales lo constituyen las arquitecturas efímeras del barroco, que intentan integrar o, más bien asimilar a la cultura campesina. Tenían una vocación estética añadida a una intención didáctica de la religión dirigida al pueblo llano. Los elementos carnavalescos, los resabios de los juegos de escarnio, los primitivos autos alegóricos, el libre deambular por las calles, lo grotesco y agresivo, en fin, lo más lúdico y lo más visceral del inconsciente popular, será encajonado en la procesión del Corpus hasta que gradualmente el rigor protocolario acabe por desnaturalizar su carácter originario, reduciendo todos estos elementos al papel de apósito festivo de la nueva escenificación social en que se despliegan los símbolos del nuevo Estado absolutista. Un Estado que se ocupa de sustituir los ritos paganos por otros cristianos, que prohibe las prácticas populares y se adueña de las calles y plazas convirtiéndolas en espacio ceremonial. Así fue en las calles de Granada, que pondremos aquí como ejemplo.

Los arreglos de los patios cordobeses, las cruces de mayo granadinas o los altares del Corpus y los arreglos de la Plaza de Bibrrambla en Granada, también con ocasión de la festividad eucarística, son los mejores ejemplos de antecedentes de las exposiciones temporales. En ellos ya encontramos el uso de los medios expositivos que hoy nos son familiares: el diorama, el panel o la dramatización. La cruz de mayo no es más que un diorama sobre la Pasión realizado en primavera con la función añadida de dar a conocer a las hijas de la casa en disposición de contraer matrimonio a aquellos curiosos que se acercan a verlo. Para la procesión del Corpus las calles eran entoldadas y alfombradas de juncia y se animaban con juegos hidráulicos, cuadros y otros refinamientos, los balcones lucían lienzos y mantones, y se componía un número variable de altares donde se detendría la procesión y que como mínimo eran cuatro: Plaza Nueva, Pilar del Toro, Zacatín y Bibarrambla. Este último era el más espectacular y fue aquí donde más se desató el refinamiento alegórico barroco. Una arquitectura efímera integraba varias calles o una gran plaza en cuyo centro se colocaba un altar conteniendo una Sagrada Forma (fig. I). Esta arquitectura se embellecía con esculturas y cuadros de los mejores artistas y se completaba con octavas de tema religioso redactadas por conocidos escritores,

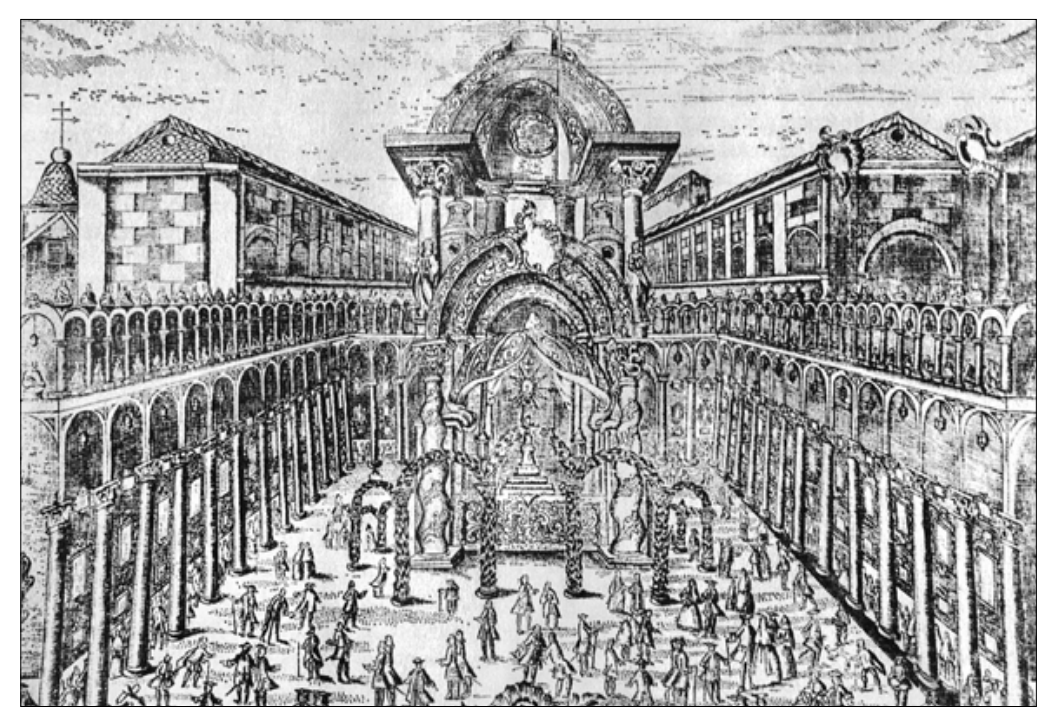


que formaban así una ronda interna y otra externa. Rocallas, cornucopias, y abigarradas cornisas remataban el conjunto.

La procesión, aparte del desfile de autoridades civiles, también tenía un alcance alegórico y didáctico mostrando a los vecinos un fragmento de historia religiosa acerca de los orígenes del cristianismo, con la historia de Santa Marta, reflejada en la Tarasca; y con la Historia de la "reconquista" cristiana de la ciudad por los Reyes Católicos, representada por los gigantes.

Durante todo el siglo XVIII la fiesta se desenvolvió conforme al mismo esquema y con una clara vocación tradicionista y barroca. Pero a finales del siglo esta manera de hacer ya no era del agrado del nuevo pensamiento ilustrado: fueron prohibidos los autos sacramentales e incluso el cortejo grotesco de "la Pública". Esto no quiere decir que todas las prohibiciones surtieran efecto, pero el caso es que el Corpus languideció. No obstante, continuaban haciéndose los adornos de Bibarrambla y la carrera procesional, aunque con menor boato.

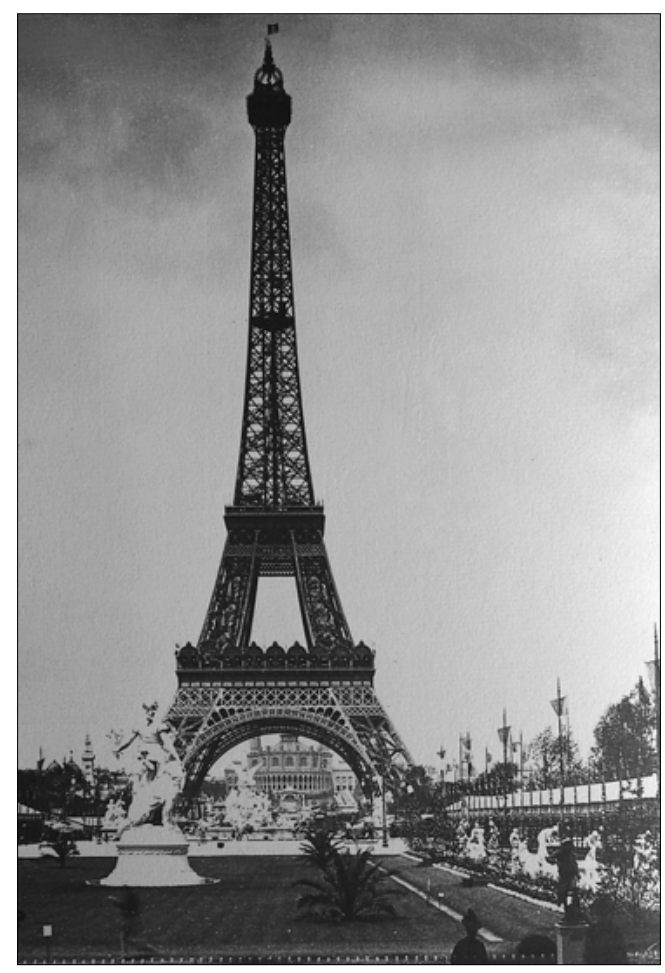

Hacia mediados del siglo XIX los temas profanos se adueñan de las cartelas de la ronda exterior de la plaza con octavas en que se comentaban temas de actualidad, poco a poco sustituidas por "quintillas" que darán lugar a las actuales "carocas" con la supresión de la ronda interior de temática religiosa. Las carocas son hoy comentarios jocosos y críticos sobre la gestión política $\circ$ acontecimientos especialmente divertidos ocurridos a lo largo del año. Su concisión y la combinación de texto e imagen son un buen ejemplo de comunicación rápida, sencilla y efectiva. Ya a principios del siglo $X X$, durante el Corpus, mientras que la pequeña burguesía acudía a bailes, conciertos y expo- siciones, el pueblo llano se arracimaba a la entrada de las barracas y se intoxicaba de vino de pasto.

La historia de las exposiciones temporales comienza fuera de España también a mediados del siglo XIX, por impulso de las exposiciones universales.

\section{Las exposiciones universales}

La sociedad laica e industrial sobreviene con el triunfo definitivo de la burguesía, que sustituye a la aristocracia en el liderazgo y el dominio social. Las exposiciones universales van a ser el emblema del triunfo de la burguesía ejemplificado en las múltiples manifestaciones de la Revolución Industrial.

El arte de exponer de la era industrial se iniciaría con las exposiciones de máquinas que comenzaron a realizarse en Inglaterra y Francia a finales del siglo XVIII. Su culminación evolutiva se encuentra en las grandes exposiciones internacionales y universales -especialmente las de Londres y París- que serían las que realmente revolucionaran el concepto de exposición, tanto para instalaciones permanentes como temporales. Los impulsos lúdicos populares van a ser conducidos en estos grandes acontecimientos hacia un lugar intermedio entre la barraca de feria, donde se exponía lo sobrenatural, lo extraordinario y lo grotesco; y los museos, pertenecientes a la cultura de las élites, y que para aquellas fechas ya empezaban a ser tradicionales. En ellas se oficiará una nueva religión, un culto al industrialismo y al progreso del que la burguesía se siente portadora. No parece en absoluto casual que la idea exacta de mercancía que late en la obra de Karl Marx le fuera inspirada por su visita a la Exposición Universal de Londres de |85।, tres años después de publicar su Manifiesto Comunista.

Las exposiciones universales, concebidas como grandes ferias populares, se propusieron mostrar al gran público el estado del mundo dominado por la burguesía occidental, de las ciencias, la Historia y las artes. Pero la diversión del gran público continuaba siendo una consideración de primer orden. Las exposiciones universales son la expresión perfecta del capitalismo entendido como diversión.

La primera exposición universal fue la Gran Exposición Internacional de Londres de I85।. Su gran contenedor de hierro y cristal, el Crystal Palace de Joseph Paxton, (un jardinero especializado en parques naturales), constituyó una verdadera exhibición del poderío industrial británico. Se demostró muy eficaz al disponer un espacio unitario y fluido donde el diseñador podía colocar prácticamente todo lo que se propusiese. El visitante quedaba atrapado por el paisaje creado a su alrededor, del que era incapaz de escaparse ante la abrumadora sugestión de una naturaleza presentada casi de forma teatral, tal como venía haciéndose en los invernaderos del siglo XIX.

Tras la exposición quedarían definitivamente fijados en la trama urbana londinense los parques de Ken- 
sington Gardens y Hyde Park. Junto a éstos, la exposición universal de Londres dio lugar a la idea de un museo permanente, el que sería Victoria and Albert Museum, el paradigma de museo enciclopédico. Más tarde se irían sumando el Science Museum, el Geological Museum y el Natural History Museum.

Las exposiciones universales después de la de Londres dejarían igualmente una huella imborrable en las tramas urbanas de las ciudades que las acogieron, con espacios de tanta representatividad pública como el Trocadero parisiense, el Parque de la Ciudadela y la colina de Montjuich en Barcelona, o el Parque de María Luisa y la Plaza de España en Sevilla.

La exposición universal de París en 1867 consagrará la idea de un gran pabellón internacional donde prevaleciese el divertimento del público ante lo sensacional por encima de las pretensiones educativas. Este divertimento se realizaba en el Campo de Marte, mientras que el pabellón en sí mismo tenía un carácter más pedagógico y educativo. Este pabellón tenía forma concéntrica y cada círculo representaba una época de la historia del mundo (fig. 3). Más tarde, durante un congreso celebrado en Madrid durante la Segunda República, la arquitecta Gertrud Stein propondría un museo ideal inspirado en el pabellón parisino de 1867: las galerías concéntricas permitirían acercarse al arte de todo el mundo en un momento determinado de la historia, mientras que las galerías radiales permitirían realizar un recorrido cronológico por el arte de un país en concreto.

En 1878 una nueva exposición se extendió a la otra orilla del Sena, con un nuevo espacio central en el Palacio del Trocadero. En 1889 se extenderían las construcciones por la Explanada de los Invalidos y el muelle de Orsay.

A España llegaría la fiebre algo más tarde, con la exposición de Barcelona en 1888. Se celebró en el Parque de la Ciudadela, una ampliación urbana extramuros de la ciudad medieval, mandado construir originariamente por Felipe V. Cataluña era entonces la primera potencia industrial de España, y la única capaz de llevar a cabo una exposición internacional con un interés semejante al que habían tenido las de otros países. Tras el arco de Triunfo de acceso al recinto (fig. 4), quedaron los edificios que albergarían más tarde un Museo de Zoología, otro de Geología y un gran invernadero. Además, estaba el gran pabellón central semicircular, que venía a ser como medio pabellón del gran edificio parisino.

La exposición de Chicago de 1893, y más tarde la de París en 1900 supusieron la incorporación de la electricidad, los efectos sonoros, y los grandes espectáculos visuales. En París, el público, colocado bajo la Torre Eifel (fig. 2) podía ver pasar ante sus ojos un rodillo pintado, de un kilómetro de largo y quince metros de alto, que le transportaba, a través de un trayecto imaginario, de Marsella a Constantinopla. A esto se añadían los juegos de luces y el trabajo de los actores delante de la tela. El cine haría pronto su entrada en las grandes exposiciones, colaborando al entretenimiento y la sorpresa del público que, en buena medida, comenzaban a interesar más que la consecución de nuevos conocimientos. Las exposiciones universales colaboraron notablemente a la popularización del cine y a su aceptación académica al final de un periplo hacia su reconocimiento social que se inicia en las barracas de feria o los nickel odeons y termina en los manuales de Historia del Arte. Los dioramas y panoramas mecanizados llegaron a ser habituales en las exposiciones siguientes como San Francisco en 1915, o Nueva York en 1939.
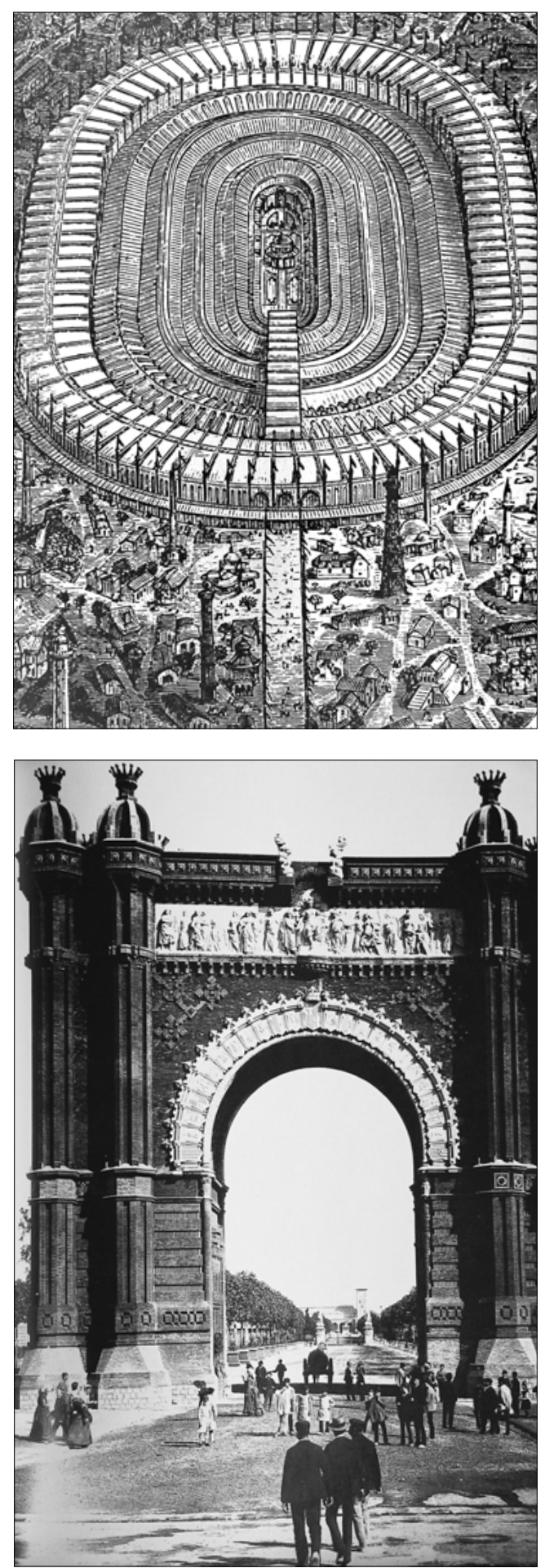
En 1929, esto es, hacia finales de la Dictadura de Primo de Rivera, tuvieron lugar en España dos exposiciones internacionales: las de Barcelona y Sevilla. En Barcelona la exposición consagraría un museo de arte que con el tiempo se convertiría en Museo Nacional de Arte de Catalunya, instalado en el edificio principal de la exposición, el Palacio Nacional de Montjuich, un enorme edificio encuadrado estilísticamente en el eclecticismo historicista. Este generaría por atracción los museos Arqueológico, Etnológico y del Pueblo Español. Y, mucho más recientemente, la Fundación Joan Miró. Frente al historicismo dominante de la exposición, contrastaba la modernidad del pabellón alemán, obra de Mies van der Rohe. Éste condensaba los principios de experimentación del Movimiento Moderno en el campo de los museos. Unos principios tan utópicos que, aparte del pabellón, van der Rohe sólo conseguiría realizar en su vida un museo, la Nueva Galería Estatal de Berlín, basada en los mismos principios de diseño. No obstante, las consecuencias de la idea de Mies van der Rohe de un espacio unitario y continuo con posibilidades de extensibilidad sobrevivirían en las décadas siguientes con realizaciones como el MoMA neoyorquino, el Sainsbury Centre for Visual Arts o el Centro Georges Pompidou de París.

En Sevilla los mayores espacios expositivos darán lugar a dos museos de considerable importancia: en primer lugar, el Museo Arqueológico de Sevilla, instalado en el Pabellón Renacimiento, de estilo plateresco; y varias décadas más tarde el Museo de Artes y Costumbres Populares de Sevilla, en el Pabellón Mudéjar. Sin embargo, no había en estas construcciones ningún afán renovador, ni el más lejano atisbo de una influencia de las vanguardias. Los edificios fueron responsabilidad de Aníbal González, un seguidor
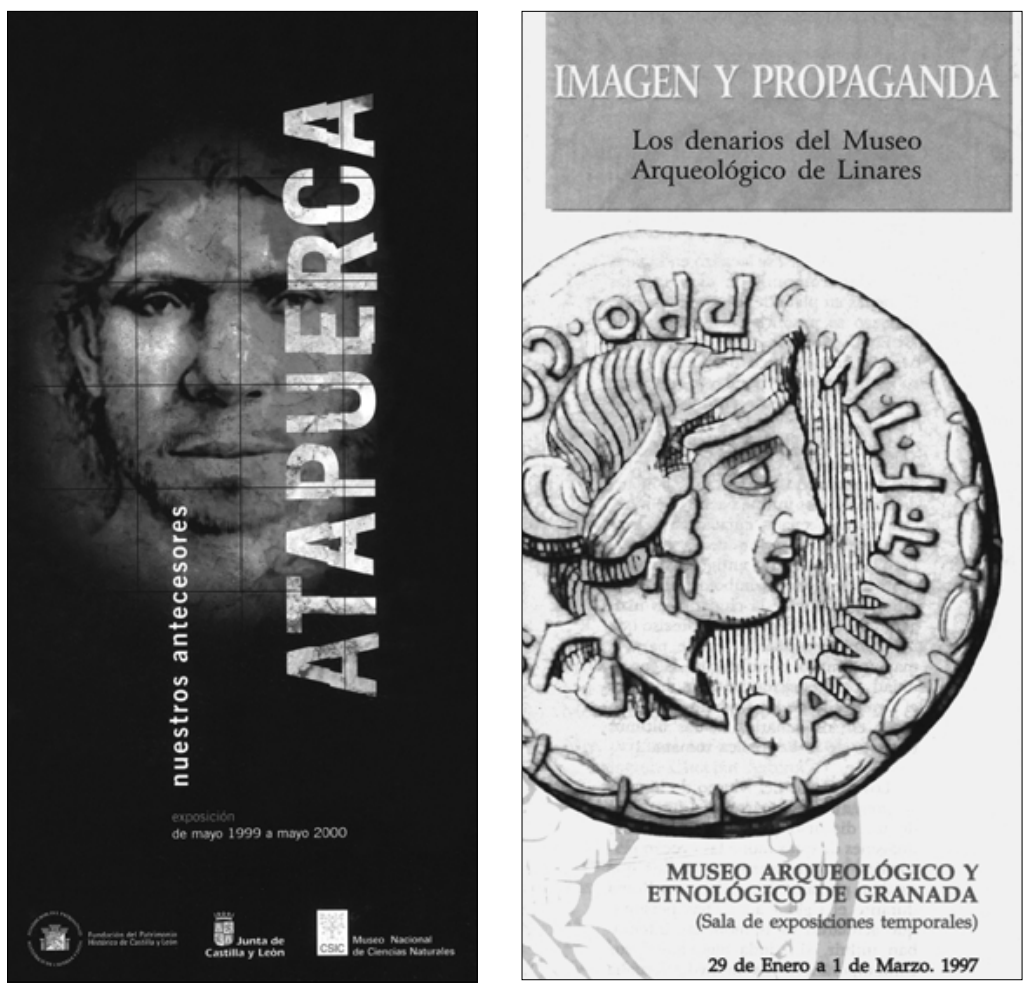

acérrimo de la línea historicista. Cuando la organización anarquista de orientación violenta La Mano Negra pretendió realizar un sonoro atentado en SeviIla, escogió a la persona de Aníbal González como reo de muerte por su representatividad en los conflictos de la construcción de la Sevilla de los años 20. El atentado fracasaría. Así pues, los pabellones sevillanos del 29 reproducen el esquema decimonónico de recorrido controlado e invariable, con sucesión de gabinetes y galerías, con un espacio central para el enaltecimiento del museo como templo del arte, que en el caso del Pabellón Renacimiento es el Gran Salón Oval, donde se instalaron en los años 40 las mejores esculturas imperiales disponibles, colocando en el centro a los dos emperadores españoles: Trajano y Adriano, este último -por añadidura- sevillano.

No obstante, la Exposición de Sevilla es difícilmente comparable con otras anteriores, pues España y menos aún Andalucía, no tenían mucho que aportar desde el punto de vista de la exhibición del industrialismo y el capitalismo. Su orientación "iberoamericana" parecía pretender colaborar con el trauma no superado del 98 y con el enaltecimiento de las glorias patrias en el sentido propagandístico del Directorio que, incapaz de transformar la realidad económico-social del país -si no más bien de llevarla a un callejón sin salida- se embarcaba en grandes obras públicas de más repercusión mediática que económica, como las carreteras o las infrastructuras hidráulicas. Los edificios, tal como acabamos de comentar, eran más bien el emblema de un historicismo casticista ciertamente retrógrado. Este regionalismo es el mismo que llama a Guichot a reclamar un programa arquitectónico que verá colmadas sus aspiraciones en el revivalismo sevillano de Aníbal González y sus seguidores. Un programa arquitectónico, paradójicamente centralista (no tan paradójicamente en realidad), que había sido explicitado por Vicente Lampérez desde su Cátedra de la Escuela Superior de Arquitectura de Madrid, que consistía en la recuperación formal de la ornamentación y la composición netamente hispánicas y que se extenderá a la filosofía restauradora proponiendo la reconstrucción de los edificios antiguos en su estilo original.

Las exposiciones de postguerra, como la de Bruselas en 1958, la de Montreal en 1967 y la de Osaka en 1970, supondrán una nueva profundización en el entusiasmo por el progreso tecnológico como bien simboliza el famoso Atomium de Bruselas que no es sino la representación de una molécula de hierro metálico. La exposición de Bruselas intentó persuadir al gran público de las posibilidades de utilización pacífica de la energía nuclear. Los audiovisuales fueron ganando la partida a las antiguas formas de animación escenográfica. Y su consagración más reciente la verán las exposiciones universales finiseculares (Sevilla, Lisboa y Hannover). La competencia que se dio en Sevilla en 1992 por producir los más sensacionales espectáculos audiovisuales sólo es comparable con la reacción que tuvo la industria cinematográfica frente a la aparición de la televisión. 


\section{Las exposiciones artísticas}

Las primeras exposiciones temporales de signo artístico y minoritario serán una concesión monárquica y despótica. Los salones parisinos de las academias borbónicas -como después los españoles- acogerían las obras presentadas a los concursos oficiales convocados con periodicidad.

La exposición universal de Londres de 185 I había mostrado que los objetos podían trasladarse fácilmente para ser mostrados en exposiciones temporales. Los promotores de exposiciones artísticas lo comprendieron rápidamente. En Inglaterra, la primera de estas exposiciones tuvo lugar en 1850, gracias a la cesión de obras del Victoria and Albert Museum a la Central School of Design, de Somerset House; durante dos años, la exposición se presentó en las diferentes escuelas de la provincia. A partir de 1852 , las actividades de préstamo fueron encargadas a un "Department of Circulation" especializado. Sus primeros esfuerzos se encauzaron a la preparación de un museo muy completo con 600 objetos, que viajó durante cuatro años recibiendo más de 300.000 visitantes. Después intentó responder a las necesidades de los estudiantes de arte más que a las del gran público.

\section{Las vanguardias}

Los vanguardistas abominaron del museo tradicional ("No nos va el templo muerto del arte"), y lo sustituyeron por un templo vivo del arte, estos es, un templo nuevo, pero templo al fin y al cabo. Un espacio sacralizado donde contemplar el arte de vanguardia -como en el caso del edificio de exposiciones de la Secesión Vienesa-, evocando el palacio de una Salomé vestida por Gustav Klimt y Koloman Moser.

Las vanguardias de las primeras décadas del siglo $X X$ colaboraron intensamente en todos los frentes de las exposiciones temporales. Mientras que el edificio de la Secesión Vienesa era un nuevo receptor de exposiciones artísticas elitistas - pero de vanguardia- destinadas a una burguesía de gustos innovadores, la contribución más interesante de la vanguardia artística al arte de exponer se produjo en el campo de encuentro del diseño arquitectónico e industrial, con sus planteamientos de la problemática formal, tanto en arquitectura como en los productos manufacturados que se exhibían para ser publicitados y vendidos, como en el caso temprano del Deutscher Werkbund alemán, fundado en 1907.

Hasta los años 20 apenas se había puesto interés en la confección del recorrido. La vanguardia alemana haría avanzar considerablemente el arte de exponer en las exposiciones sobre arquitectura y diseño de interiores: Zurich, Viena, Stuttgart, Berlín, etc.. La Bauhaus es el paradigma - durante los años 20- de la fusión de las nuevas corrientes en la arquitectura y el diseño. La exposición de artes decorativas de 1925 en París fue la primera en emplear paneles en los que se exponían tanto los objetos como las explicaciones complementarias.

En la exposición "Pressa" de Colonia en 1928, dedicada a la prensa y la imprenta, El Lissitzky empleó por vez primera el fotomontaje mural para simbolizar la importancia de la prensa como vehículo del saber y útil propagandístico. Dirigió a veintiocho colaboradores para confeccionar un gigantesco collage en el centro del pabellón soviético, para simbolizar la difusión de la prensa soviética en todas las repúblicas de la Unión.

En 1930, Gropius y Bayer diseñaron el pabellón de la "Deustcher Werkbund" en la Exposición de Artes Decorativas de París, empleando montajes fluidos e imaginativos. Reproducía un edificio de diez plantas en el que Walter Gropius diseñó la sala de reuniones; Marcel Breuer una sala de juegos, otra para audiciones de radio y el apartamento piloto. MoholyNagy diseñó la sección dedicada a nuevos materiales y a una estafeta de correos estándar. Dispusieron los objetos repetidos en series, en grandes vitrinas murales, que producían la impresión de un flujo orgánico. Gropius utilizó un puente para que los visitantes tuvieran una panorámica de la exposición antes de atravesarla. Herbet Bayer diseñó la sala dedicada a la arquitectura y el mobiliario. Pintó en el suelo unas pisadas que indicaban el camino a seguir y el orden de los textos escritos. Las paredes donde se exponían las fotografías estaban colocadas en planos inclinados y los muebles de diseño, tales como sillas, también fueron suspendidos de las paredes en lugar de en su posición natural.

Con la llegada del estalinismo y el nazismo, Suiza tomará el relevo y preservará el recuerdo en el diseño de vanguardia. Así por ejemplo en la Trienal de Milán de 1936, donde se siguieron empleando los collages, las fotografías fragmentadas y giradas, o los elementos desmontables de madera y metal. El diseñador Max Bill prestó una atención particular a los colores: rojo vivo, rojo oscuro, amarillo, negro o violeta cubrían las paredes de las salas y de las vitrinas.

La Exposición Internacional de 1937 marca el punto de triunfo del academicismo moderno sobre las vanguardias. Como ejemplo significativo, ante la imposibilidad de construir las Unidades de Habitación de Le Corbusier, éste se negó a montar su pabellón de tela de los Tiempos Modernos, una gran carpa de 1.600 $\mathrm{m} 2$ donde iban a exponerse las conclusiones de los CIAM (Congresos Internacionales de Arquitectura Moderna). La vanguardia alemana emigró en bloque (Gropius, Moholy-Nagy, Bayer) a los Estados Unidos, donde se prolongaría durante un cierto tiempo el ideal de la modernidad.

\section{Las campañas institucionales}

Durante la II Guerra Mundial las exposiciones prácticamente cesaron, pero se obtuvo una experiencia positiva de las propagandas gubernamentales que debían expresarse de forma clara y directa para 
comunicarse con todo el espectro de la población. Un buen ejemplo de esta lección aprendida fue la exposición Britain Can Make It de 1946. Se emplearon recursos sumamente efectivos, como los signos pictográficos, el diseño tridimensional, la iluminación exclusiva de las vitrinas, etc.

Pero el favor del público se ganó definitivamente después de la Segunda Guerra Mundial, especialmente por las exposiciones consagradas a las Bellas Artes. Las que se refieren a la ciencia y la historia son en general de origen más reciente y eran menos numerosas hasta los años 60. La UNESCO, por ejemplo, desplegó una gran actividad, con exposiciones compuestas de paneles explicativos a los que a veces acompañaban algunos objetos tridimensionales para explicar problemas científicos, así como sus propios programas y proyectos en materia de ciencias. En este mismo medio surgieron los museobuses.

La exposición The Peoples of Britain de 1951 marcó un nuevo hito con vitrinas con modelos iluminadas independientemente, dioramas y artefactos, todo ello separado del público por barreras que lo distanciaban. Estamos frente a los antecedentes de la exposición interpretativa actual.

Durante los años 60 se puso de moda en Inglaterra un tipo de montaje alejado de fines didácticos, de tipo teatral, a base de cuadros, tomado del mundo de la escena y las figuras de cera. Así se realizarían durante los años 60 y 70 las exposiciones sobre Diaghileff, Shakespeare o Lord Byron.

\section{Los bolckbusters o tut-shows}

Pero la década de los 70 está marcada por las exposiciones grandes y espectaculares, conocidas como blockbusters ("bombas rompedoras"), muy costosas y desplegando un aparatoso mecanismo publicitario que garantizara el éxito de la operación. Es algo comparable a las películas en Cinemascope, que querían ganar al público por medio de la espectacularidad después de los primeros signos de la crisis cinematográfica. Los temas eran: Tutankhamun (1972), The Genius of China (1973), Pompeya (1976), El Dorado (1978), etc. El modelo se extendió rápidamente a otros países europeos. Una estupenda descripción de este tipo de acontecimientos fue realizada por Peter Greenway en su película El vientre del arquitecto.

Todas ellas manejaron presupuestos antes nunca vistos, cobraron entrada y fueron acompañadas de catálogos que alcanzaban la categoría de libros de considerable volumen y primera calidad. Asimismo, eran publicitadas con presupuestos similares a los lanzamientos industriales, del tipo de la industria automovilística o los electrodomésticos. En definitiva, no se emprendían si el éxito no estaba garantizado, ya que tenían vocación de atraer grandes masas e ingresar sumas importantes de dinero. Estas exposiciones son en buena medida responsables de la popularización del arte y de la Historia.
Las grandes exposiciones temporales de los años 70 fueron el principio del fin de la hegemonía de los museos en el terreno de las exposiciones. A partir de ahora, las instituciones públicas y las entidades financieras, conscientes del atractivo de las exposiciones temporales, van a hacerse con el protagonismo de su producción, en la senda acumulativa de la mercantilización de los bienes culturales.

\section{La llamada a la cordura}

El entusiasmo despertado por las exposiciones temporales en vísperas de los años 80 llegó a provocar propuestas más o menos utópicas y reactivas por parte del mundo de los museos. Así fueron las de Franco Minissi, catedrático de Museografía en la Universidad de San Ivo en Roma, que defendía un equilibrio redistributivo de las colecciones de los museos. Proponía incluso la posibilidad de crear museos sin fondos $\mathrm{o}$, al menos, de convertir la exposición temporal en parte del modo de ser cotidiano del museo. Reivindicaba mayor espacio y relevancia arquitectónica para el área de exposiciones temporales de los museos. Ésta debería ser versátil para poder recibir todo tipo de exposiciones. A su vez, el museo debía contar con una infraestructura reutilizable e intercambiable de una exposición a otra, y de un personal familiarizado con su manejo.

Minissi resumía estas características en "facilidad de uso", "economía relativa" e "integrabilidad". La "facilidad de uso" consiste en la posibilidad del personal del museo de desarrollar autónomamente las operaciones de adaptación de la estructura expositiva a las exigencias de cada muestra, desde la realización de un croquis del recorrido hasta el panel informativo, la vitrina, el pedestal, el soporte de una fuente luminosa, etcétera. La "integrabilidad" supone la posibilidad de aumentar el número de estructuras expositivas en paralelo con el eventual crecimiento de la colección, que puede afrontar imprevisibles adquisiciones permanentes o temporales. La "economía relativa" de tales estructuras y de su integración eventual está implícita en la facilidad de uso que vincula a la administración del museo para no recurrir a ayuda especializada, y en segundo lugar, está determinada por el uso apropiado de los materiales y las tecnologías. Se trataba en parte de un problema de diseño, tendente a la modularidad o a la adición telescópica de materiales. Un metal preciado como el bronce o el estaño cuestan bastante más que el hierro, pero al contrario que éste, su mantenimiento deviene prácticamente nulo. Unos raíles para grupos eléctricos son indudablemente más costosos que una instalación tradicional con puntos de luz fijos, pero su uso resulta fácil y su polivalencia prácticamente ilimitada. Un sistema de paneles modulares flexibles en los formatos mínimos en que puedan componerse y con el máximo posible de formas y dimensiones, comporta una serie de tareas de acabado mayores con la misma superficie que los paneles enteros e incluso un costo mayor, pero la reutilización permanente de los primeros respecto a la frecuente inutili- 
zación de los segundos resultará a la larga indudablemente más económica. La modularidad y facilidad de composición de las vitrinas como de los paneles supone a largo plazo un ahorro sensible.

Pero, a pesar de aquellas buenas intenciones, la realidad acabó imponiéndose. Las exposiciones temporales que atraen las mayores cantidades de público y al mismo tiempo emplean objetos genuinos como clave de su contenido han llegado a ser excesivamente costosas y poco adecuadas para los museos de formato mediano o pequeño, y por ello suelen realizarse fuera de estos centros. Por añadidura, los museos pequeños carecen de espacios e instalaciones adecuadas para este tipo de eventos. Una exposición temporal requiere de un espacio diáfano y flexible dispuesto a recibirla y de un personal técnico acostumbrado con el montaje de los dispositivos de exposición, y los museos suelen carecer de estas condiciones. En consecuencia han de conformarse con realizar pequeñas exposiciones en el campo de las bellas artes $y$, en menor medida, en otras áreas temáticas.

\section{Las tendencias actuales en las esposiciones temporales}

\section{La proliferación}

Las exposiciones temporales realizadas en España en el último cuarto del siglo XX han superado cuantitativamente todo lo realizado anteriormente en el campo artístico, pero aún más en el resto de las temáticas.

El primer signo de la proliferación es que prácticamente todos los agentes sociales se han mostrado interesados en la producción o exhibición pública de exposiciones temporales.

En primer lugar, las administraciones: museos, conjuntos monumentales, universidades, ayuntamientos, diputaciones y gobiernos de comunidades autónomas cuentan hoy por hoy con salas de exposiciones temporales en cualquier capital de provincia española o europea.

Con la transición democrática España se convertirá en un Estado de las Autonomías. Este hecho dará lugar a una particular forma española de encarar los procesos de generación de identidades en el contexto finisecular de la sociedad postindustrial. La Administración central y las Administraciones Autonómicas coincidirán en este proceso de formación identitaria de forma digamos complementaria, aunque a veces, de forma contradictoria. Así, mientras que las instancias estatales (Patrimonio Nacional, Ministerio de Obras Públicas, C.S.I.C. y, sobre todo el Ministerio de Cultura) procurarán hallar las claves de la identidad de España en su historia, las Comunidades Autónomas intentarán hacer lo mismo en sus territorios.

\section{EL MUNDO IBÉRICO: UNA NUEVA IMAGEN EN 2.000}

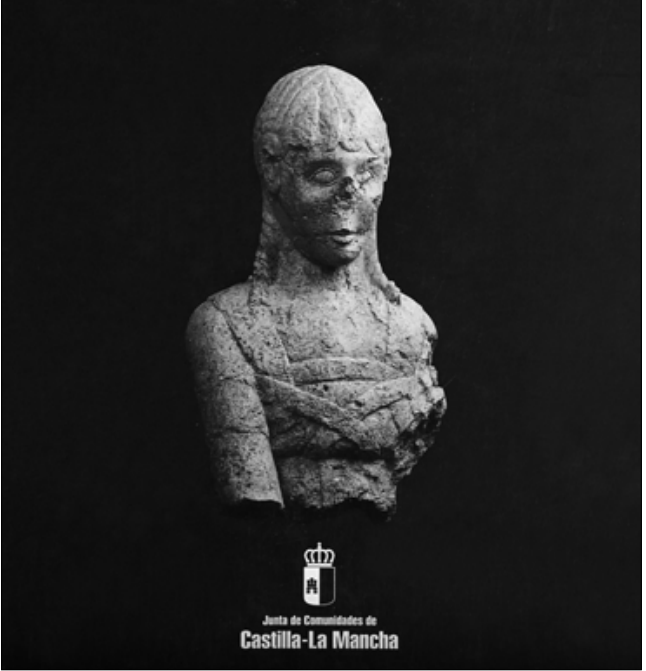

El Ministerio de Educación y Cultura inició con la transición democrática una serie de exposiciones de planificación centralizada del tipo Bellas Artes 83, confeccionadas por todos y cada uno de los museos provinciales, en las que se exponían los últimos trabajos arqueológicos o las nuevas adquisiciones de obras de arte. Eran exposiciones de bajo presupuesto, carentes de diseño, con escasa o nula publicidad. Eran, en fin, exposiciones que empezaban a ser poco adecuadas para aquel tiempo. Más adelante, y adecuándose a las nuevas circunstancias, la Administración Central se dio a la realización de exposiciones que normalmente no estaban restringidas territorialmente, intentando abarcar todos los periodos históricos, tal como sugieren los títulos de algunas de sus exposiciones: Atapuerca, Los griegos en España, El legado de la Hispania romana, Bronces romanos en Hispania, Reyes y Mecenas, Velázquez, Los Puertos Españoles en la Historia, las dedicadas a Carlos V y Felipe II, etc.

Las Comunidades Autónomas por su parte iban a subrayar las peculiaridades identitarias que justificaban las nuevas instancias de autogobierno. En las nacionalidades históricas se han realizado programas concienzudos de realización de exposiciones que subrayaran los rasgos diferenciales. En el caso catalán por ejemplo hemos de reseñar la producción de exposiciones itinerantes populares, destinadas a las localidades pequeñas, sobre aspectos específicos de la catalanidad, como la tenora, un característico instrumento de viento de origen y desarrollo exclusivamente catalanes. Junto a éstas, otras de mayor formato dedicadas al Liceo de Barcelona o El Islam y Cataluña, dos términos difíciles de casar espaciotemporalmente. Éstas tienen lugar, fundamentalmente, en un nuevo museo nacional: el Museo de Historia de Cataluña.

El País Vasco también aspira a la consecución de museos de alcance nacional y nacionalista, como el 


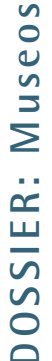

Museo Etnológico Vasco de Bilbao, donde desarrollar sus propias exposiciones temporales, como por sólo poner un ejemplo, una dedicada a los pastores vascos en la emigración a Norteamérica.

Otras Comunidades no han logrado hacerse con este espacio pero han realizado importantes esfuerzos en el mismo sentido. Así por ejemplo, la exposición sobre los pobladores prerromanos de Asturias y León (Los Astures) fue una operación diversa y compleja. Con cinco sedes diferentes supuso la puesta en valor de uno de los castros más importantes de Asturias, la Campa de Torres, así como de unas termas romanas en el mismo centro de Gijón, las termas de Campo Valdés. La exposición central sobre los astures se localizaba en el antiguo instituto de Enseñanza Media, el Instituto Jovellanos. Una exposición complementaria, algo menos didáctica y más espectacular en cuanto a diseño y montaje se desarrollaba en la Colegiata de San Juan Bautista-Palacio de Revillagigedo, dedicada a la explotación de oro en Asturias en época prerromana y romana. Finalmente, una exposición sobre la historia de Gijón se desarrolló en la nueva Torre del Reloj que sustituyó a una antigua arruinada, también en el núcleo central del casco histórico de la ciudad.

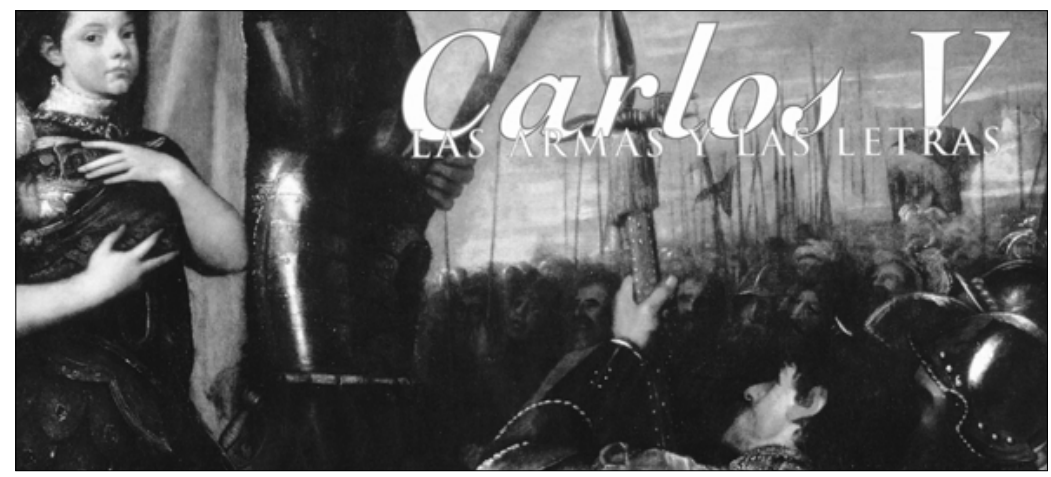

En el caso andaluz, el Primer Plan General de Bienes Culturales se proponía convertir alguno de los edificios institucionales de la Exposición Universal de Sevilla de 1992 en un museo de Historia de Andalucía, pero esta idea no llegaría a concretarse. En su defecto, las exposiciones temporales han sido abundantes. Las más tempranas fueron Andalucía y el Mediterráneo y Al-Andalus. Las Artes Islámicas en España. Más tarde, con la creación de la Fundación El Legado Andalusí se iban a realizar a partir de 1995 al menos doce exposiciones de gran formato en esta misma línea !.

El Arte Islámico de Granada y su reino, El Mudéjar iberoamericano. Del Islam al Nuevo Mundo, El Zoco: Vida económica y artes tradicionales en al-Andalus y Marruecos, Agua y Agricultura en Al-Andalus, Literatura y Música en AlAndalus, Arquitectura en AlAndalus, Al-Andalus y el Mediterráneo, Andalucía en América. El Legado de Ultramar, El Legado Cientííco de Al-Andalus, La imagen romántica del Legado Andalusí,

Música y Poesía del Sur de AlAndalus, Aromas de Al-Andalus, etc. exposición sobre la aspirina (Blanca y Redonda), o a Chanel financiando e itinerando una exposición científica y didáctica sobre la perfumería.

Finalmente, y esto es una auténtica novedad recientemente incorporada, la Iglesia ha decidido dar el salto y poner en valor su colosal patrimonio en exposiciones de contenido y pretensiones pastorales. Las pioneras fueron tal vez -al menos en nuestro país- las realizadas en las catedrales castellanas en la serie Las Edades del Hombre. El proyecto comenzó en Valladolid, y continuó en Burgos, León, Salamanca, y Astorga. Su carácter novedoso y su increíble éxito tienen mucho que ver con un diseño audaz que emplea las técnicas multimedia en el proceso de comunicación. La cantidad de hijuelos que ha generado promete convertirse en algo estable: así podemos mencionar la dedicada a Esculturas de Berruguete en la Catedral de Burgos, o las que en el año 2000 se celebraron en las catedrales de Granada y Jaén.

En la Abadía de Melk (en Austria), aquella que inspiró a Umberto Eco su novela El nombre de la rosa, una exposición intentaba en el año 2000 una aproximación al misterio de la Creación apoyándose también en técnicas multimedia, mezclando grandes collages fotográficos y efectos luminosos con obras de arte sacro de primerísima calidad.

\section{La diversificación}

Ante tal proliferación, la variedad tipológica de las exposiciones ha llegado a ser enorme. Hoy por hoy se realizan exposiciones de todo formato y de todo coste. Las hay que itineran (las menos) y que sólo se realizan una vez. Las hay que duran un mes, varios meses (caso de las integradas en espacios monumentales o en las nuevas exposiciones universales (Sevilla, Lisboa, Hannover); o incluso varios años, como en el caso de la INFOBOX de Berlín. Entre 1995 y 2000, un edificio pensado para ser efímero, mostró al público los grandes proyectos de arquitectura postmoderna desplegados en el Berlín reunificado. Una vez concluidas las operaciones inmobiliarias referidas, la instalación fue desmontada.

El caso de la INFOBOX ilustra a la perfección la evolución sociopolítica europea. Una exposición realizada sólo una década antes bajo el título Renovación urbana cautelosa exponía los resultados de un programa socialdemócrata y de amplia participación social en la rehabilitación del barrio histórico de Kreuzberg en el mismo Berlín occidental. La INFOBOX, sin embargo, nos ha mostrado abiertamente la autocomplacencia del neoliberalismo triunfante.

En la mayor parte de las exposiciones se muestran objetos genuinos, pero no en todas. La herencia de aquellos programas didácticos desarrollados durante la Segunda Guerra Mundial, y de la experiencia de los museos no de bellas artes va a dar lugar a un tipo de exposición muy preocupado por transmitir conocimientos a diversos niveles de público. En éstas pue- 
den emplearse objetos genuinos, aunque esta no es una condición imprescindible. En muchas ocasiones llega a prescindirse de las piezas originales en favor de los montajes "interpretativos" con todo tipo de dispositivos: maquetas, dioramas, audiovisuales, paneles, holografías. Las piezas pueden ser sustituidas por copias, réplicas o reproducciones o estar completamente ausentes. A menudo han venido realizándose exposiciones únicamente con paneles, como la del Arte rupestre peninsular, resultado de la documentación realizada para la declaración del arte rupestre ibérico como Patrimonio de la Humanidad, - La sociedad ibérica a través de la imagen.

El problema de la presencia de objetos originales será siempre objeto de debate entre los profesionales de la Museología. Una solución al alto coste que plantean las tareas de conservación (transporte especializado, seguros, corretajes, etc.) es el uso de réplicas, reproducciones o copias. Los detractores de las réplicas señalan la pérdida del impacto psicológico de ciertos objetos y obras artísticas, sobre todo aquellas que han sido convertidas en fetiches por la publicidad y los medios de comunicación de masas. El problema es indudablemente menor en los museos de ciencia y técnica, aunque siempre habrá quien desee ver efectivamente la primera máquina de vapor construida por Watt, o el primer puente de hierro de Ironbridge y ningún otro. Pero veamos un curioso ejemplo que puede desmitificar estos hechos.

La exposición El museo de los museos, abierta en 1988 en Florencia y que durante 1989 recorrió Parma, Milán y Roma, levantó la polémica. La idea de mostrar 120 obras de arte de todo el mundo, consideradas entre las más famosas, pero que eran "falsas", es decir, reproducidas ex profeso, a unos entusiasmaba y a otros escandalizaba. Ver la Venus del Espejo de Velázquez, la Anunciación de Fra Angélico - La Flagelación de Piero della Francesca, sabiendo que no son de la mano de sus grandes creadores, sino simples imitaciones, no dejaba de causar un cierto efecto en el visitante. El haber mezclado con malicia a las obras "imitadas" otras veinte obras "originales", colaboraba sustancialmente a la provocación. Los que las reconocían enseguida se sentían satisfechos, como demostrando que ninguna imitación podrá nunca sustituir la emoción del original. Pero hay quién reconoce el esfuerzo de los que trabajan de este modo porque piensan que la copia puede ser un modo de que el gran público pueda admirar grandes obras.

Un ámbito especialmente innovador en este sentido ha sido el de las cinés-cités. Las denominadas "exposiciones-espectáculo" o "cinés-cités" combinan elementos propios de la exposición y del teatro, resaltando aquellos aspectos que tienen una relación especial con la percepción sensorial. La exposición espectáculo es dirigida por un autor (no un comisario), que debe montar un escenario donde el decorado, la imagen y el sonido sean capaces de crear una ilusión y comunicar una idea o una emoción. No tie- nen por tanto una intención exactamente didáctica. Sin pretender explicar nada demasiado concreto, se invita al público a tocar, a deambular libremente por un universo de fantasía y de ensueño en el que todos los sentidos están implicados. Además, no existe un itinerario prefijado.

François Barré se considera el fundador de las cinéscités. La primera de éstas fue probablemente La traversée de París, de 1989. La idea central era la Defensa de la Bastilla, un auténtico símbolo de la historia de París y del poder político en Francia. Ocupando unos $7.000 \mathrm{~m} 2$ se sucedían dibujos animados, maniquíes, voces, músicas y textos de autores prestigiosos que podían escucharse individualmente con ayuda de una suerte de audioguía a través de cascos infrarrojos. El espectador era invitado a participar haciendo uso de todos sus sentidos, tocando, escuchando, viajando o degustando licores.

Otra célebre ciné-cité fue Les Dessous de la Ville, inaugurada en 1991. Tuvo como tema el subsuelo de París: canteras, cloacas, excavaciones arqueológicas, criaderos de setas. Se componía de 19 decorados realistas animados con vídeo y una banda sonora.

También en 199| se inauguró La Mémoire d’Égypte, dedicada a la Egiptología. Constaba de tres secciones: antes, durante y después de Champollion. Tenía la estructura de una ópera dividida en seis actos cuyo hilo argumental era la vida de Champollion. Ficción y rigor documental se mezclaban de tal manera que se podía contemplar las piezas originales de la colección del Louvre, la reconstrucción de la vida de los egipcios con la ayuda de los vídeos, o encontrarse con las figuras parlantes de Champollion y su hermano representados por actores profesionales. La exposición podía recorrerse con ayuda de la audioguía de infrarrojos o bien sin los cascos, dejándose llevar simplemente por otros estímulos sonoros. Tuvo más de 500.000 visitantes.

Esta misma idea encontró proyección en alguna realización museográfica próxima a nuestro entorno, como el Museo de la Torre de la Calahorra en Córdoba, promovido por la Fundación Roger Garaudy. El pequeño museo histórico de Córdoba que se encontraba en la Torre de la Calahorra fue asumido por la Fundación Roger Garaudy y convertido con gran éxito en una especie de museo de Al-Andalus o de "las tres culturas" en su coexistencia cordobesa. Seis pequeñas salas acogen una presentación a base fundamentalmente de maquetas con audioguías de infrarrojos que, dedicada en sentido genérico al mundo andalusí, intenta abundar en las virtudes y beneficios de la multiculturalidad. Así, tranquilamente sentados en un banco, podemos escuchar las voces de Maimónides, Averroes y Alfonso $X$ el Sabio que nos leen los mejores aspectos filosóficos de su obra acerca de la convivencia y otros temas. Al mismo tiempo, las luces enfocan alternativamente a un maniquí que representa a cada uno de los personajes. Una proyección múltiple de diapositivas con una duración de 55 minutos realiza un vertiginoso, singular e idealista repaso de la his- 


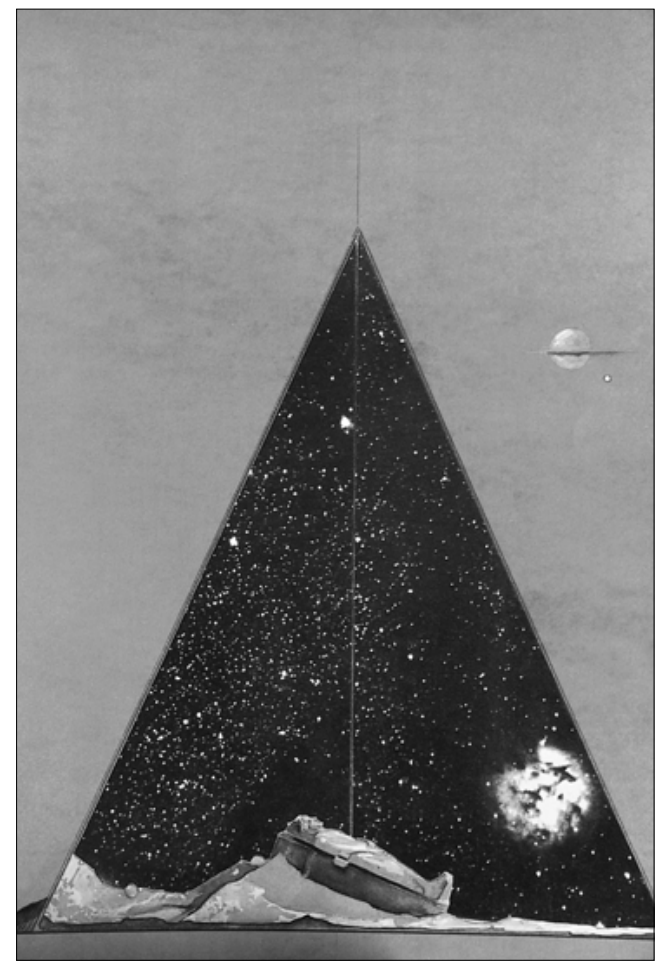

toria de la humanidad con textos del propio Garaudy. El resultado es un delicioso kitch hasta el punto en que éste puede ser delicioso y, a veces, algo más allá. El éxito fue rotundo, con 80.000 visitantes en el primer año de apertura.

Por el contenido, las exposiciones han llegado a ser extraordinariamente diversas. Así por ejemplo continúa habiendo exposiciones artísticas de diversa orientación, ya sean históricas (antológicas, temáticas, generacionales...), o de arte contemporáneo de carácter comercial (DOCUMENTA de Kassel, Bienal de Venecia, ARCO, etc.). Éstas continúan siendo el espacio natural de comunicación entre el artista y el público, ya sea éste comprador o no. Sin ellas, el proceso de creación y comunicación artística sería inexistente, si bien es cierto que una minoría de marchantes y críticos sigue determinando qué es lo que tiene derecho a acceder a estos espacios y lo que no.

Entre las arqueológicas se perfila una notable diferencia entre aquellas que exponen simples colecciones descontextualizadas y procedentes en buena medida del expolio, de aquellas que pretenden transmitir unos contenidos científicos en el contexto de una práctica arqueológica moderna y democrática.

En las exposiciones de carácter histórico se ha abusado tal vez de los aniversarios y efemérides que, no obstante, constituyen una ocasión inmejorable para la puesta al día y -sólo a veces-, para la popularización de contenidos históricos.

Entre las etnológicas, si bien continúan haciéndose exposiciones temáticas al modo tradicional sobre aperos de labranza, candiles o tauromaquia, se están explorando otros temas como la moda, la almadraba, el cabaret, el perfume, las razas, el futuro demográfico de la Humanidad, las ciudades, etc.
Por último están las cientíicas en las cuales ha sido importantísima la aportación de los nuevos Centros de Ciencia. El Parque de las Ciencias de Granada, la única institución de estas características existente en Andalucía forma ya hace algún tiempo parte integrante del circuito de intercambio de exposiciones temporales que funciona entre estos centros.

Otra línea interesante es la de aquellas exposiciones que pretenden una aproximación interdisciplinar, concitando disciplinas científicas diversas.

En realidad, y en definitiva, las exposiciones que más éxito popular y más eficacia comunicativa tienen son aquellas en las que se consuma el encuentro de las dos tendencias expositivas que mencionaba al principio del artículo: la exposición elitista y la exposición popular. En éstas, sigue habiendo objetos genuinos, dando ocasión para la experiencia fetichista o técnica, y para el encuentro directo con la obra de arte; pero además, se emplean mecanismos comunicativos capaces de "enganchar" al visitante, consiguiendo esa pregnancia que sólo prestan la participación, la posible interacción, la identificación emotiva, y el sentimiento lúdico del encuentro entre los promotores y diseñadores y el público.

\section{Las características sociológicas}

La exposición temporal suele ser más asequible que las exposiciones permanentes porque su horario se presta más para la afluencia de los trabajadores, mientras que los horarios de los museos son más restrictivos y menos acordes con los horarios del público en general. Así, suele darse la paradoja de que muchos ciudadanos conozcan museos en lugares muy alejados de su domicilio, que frecuentan durante las vacaciones, mientras que no conocen los museos de sus propias localidades de origen, o no los visitan con asiduidad.

En este mismo hecho incide el carácter eventual de las exposiciones, presentadas por una maquinaria publicitaria de la que las exposiciones permanentes carecen. El hecho de que las exposiciones estén sujetas a un periodo más o menos corto de tiempo las convierte en eventos que es preciso aprovechar, mientras que la exposición permanente del museo siempre se encuentra ahí. Su visita se puede demorar, y de hecho, se demora indefinidamente.

La ordenación convencional de los museos suele basarse en criterios cronológicos, topográficos o tipológicos, lo que los hace descartar otros múltiples enfoques temáticos que seguramente Ilegarían al público con más eficacia y de forma más directa. El museo ha de seducir en primer lugar al visitante $y$ después atrapar su atención, una vez que ha penetrado en las salas. Pero esto no es lo más corriente. Por el contrario, la publicidad y las propuestas temáticas convierten a las exposiciones temporales en un gancho que, a la postre, puede incluso beneficiar considerablemente la frecuentación al propio museo. 
Las exposiciones son un campo interesante, fluido y versátil, para la experimentación de las técnicas expositivas, las técnicas de marketing y comunicación de masas, etc. Las áreas permanentes son más resistentes a los cambios y más reacias a la experimentación.

El lugar más idóneo para la realización de estas exposiciones, o al menos de aquellas en que participan objetos genuinos, ya no hace falta decirlo, está en los museos. En primer lugar, porque los objetos de mayor interés suelen encontrarse en los mismos y sus movimientos son costosos (transporte especializado, embalajes sofisticados, seguros) así como peligrosos para las obras, todo lo cual desaconseja su movimiento. En segundo lugar, porque las exposiciones temporales constituyen la ocasión de romper la rigidez de la exposición permanente presentando al público los objetos que forman parte de la colección del museo desde perspectivas tan variadas como lo permita la imaginación de los promotores, revalorizando su contenido y su potencial informativo. Pero sobre todo, porque la exposición temporal se ha mostrado como un fenómeno incontenible en nuestra sociedad postmoderna y postindustrial, en la que el ansia de conocimiento de sectores cada vez más amplios de la población, respaldados por la retórica democrática, ha disparado las dimensiones del fenómeno.

Las nuevas presentaciones tienen en fin, una importante componente pragmática, lúdica, mediática e híbrida a la hora de acercarse al conocimiento. Y esto coloca a los organizadores de exposiciones entre el ya viejo paternalismo tardofranquista y la vanalización de dar al gran público lo que quiere ver, es decir, la disneyzación, intentando al mismo tiempo no perder el papel y el nivel de los contenidos.

Para muchos visitantes - como ya hemos indicado-, el primer acercamiento a un museo se realiza con ocasión de una visita escolar obligatoria, o bien con ocasión de una exposición temporal. Además, con ocasión de las exposiciones temporales, los museos exponen parte de sus fondos que habitualmente no están a disposición del gran público.

Todas las circunstancias aquí expresadas recomiendan por tanto que los museos -como reivindicaba Minissi- incorporen las exposiciones temporales a su funcionamiento habitual. Pero para ello, insistiremos de nuevo, es preciso que cada museo cuente con un espacio mínimo dedicado a la realización de estas actividades, dotado de la flexibilidad necesaria para la creación de espacios diversos según la necesidad de cada exhibición, así como de unos soportes expositivos flexibles, adaptables a cada necesidad, que no se desechan una vez concluida la exposición, con el ahorro consecuente y su rentabilización económica a largo plazo. Esto se refiere a vitrinas, soportes de paneles, pedestales, iluminación, etc., así como a un personal mínimo que esté familiarizado con el manejo y montaje de los mismos, y que puede ser el propio de mantenimiento del museo, aunque hoy por hoy, sólo una pequeñísima minoría de los museos cuenta con este tipo de personal. Todo ello conlleva inversiones iniciales de cierta consideración, pero que como decimos, serían aprovechadas sobradamente en su proyección temporal.

Actualmente, sólo unos pocos museos gestionados por la Comunidad Autónoma vienen realizando exposiciones temporales de producción propia: el Centro Andaluz de Arte Contemporáneo, o el Patronato de la Alhambra y Generalife. Otros que las realizan, aunque con menor frecuencia son el Museo de Bellas Artes de Sevilla y el Museo de Artes y Costumbres Populares, también de Sevilla. Del resto, la mayoría ha de conformarse con recibir exposiciones de pequeño y mediano formato de préstamo gratuito o, sencillamente, ya han olvidado cuándo fue realizada la última exposición temporal en el centro.

Este funcionamiento habitual, brindaría además la oportunidad de alcanzar un equilibrio redistributivo de las colecciones, al hacer itinerar las exposiciones en la medida de las posibilidades por medios comarcales, hacia los museos locales, intercambiando recursos y objetos con los mismos, y procurando recontextualizar muchas piezas que hoy duermen, improductivas, su sueño idealista en los almacenes de los museos tradicionales.

\section{La perspectiva técnico-profesional}

El crecimiento en el volumen de las exposiciones temporales ha supuesto el surgimiento de empresas especializadas que gestionan el transporte, los seguros, el diseño o el montaje de las exposiciones.

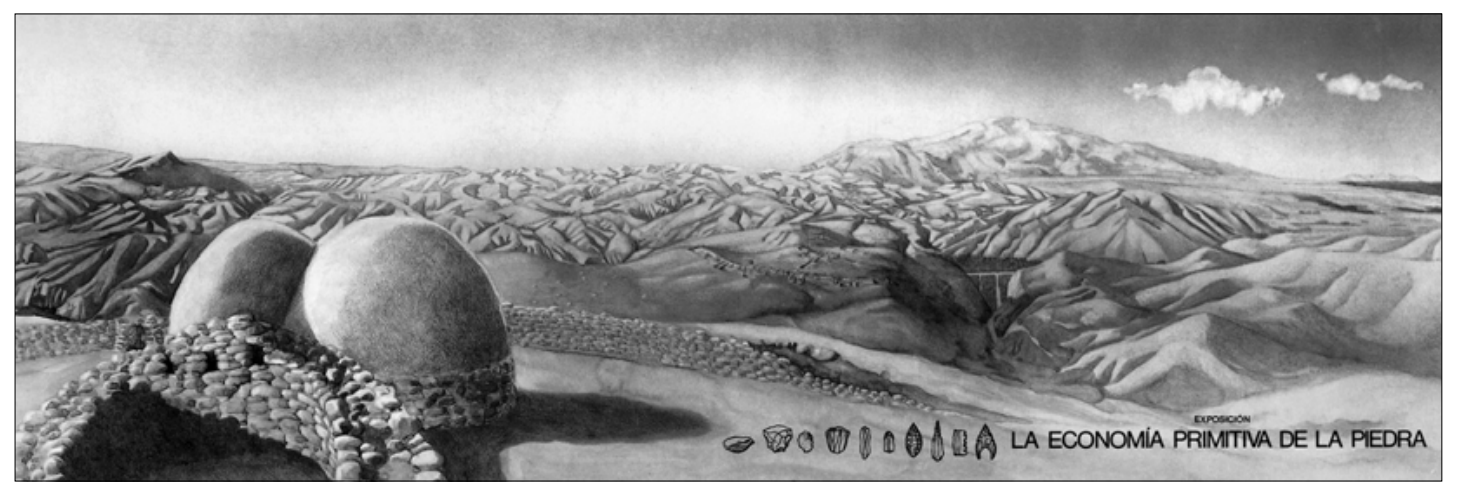


Cada vez más existen profesionales formados en la Museología y Museografía que, no obstante, aún no han alcanzado su plena instalación en el mundo de las exposiciones. Lamentablemente, aún hoy, la mayor parte de las exposiciones son comisariadas por algún entendido en el tema de que se trate, normalmente un profesor universitario, que desea volcar toda su formación científica especializada en la exposición, lo que da lugar a los típicos errores del principiante: sobresaturación de información o de objetos, textos ilegibles o incomprensibles, falta de jerarquización y conceptualización, ausencia del lenguaje visual, falta de contextualización, etc. A menudo también se desatienden las cuestiones relacionadas con la conservación, esperando que los seguros solventen una posible eventualidad negativa. El deterioro de las obras de arte es lento e irreversible y, a menudo, no es fácilmente perceptible sino por acumulación. Las fichas de préstamo no siempre son muy exigentes a este respecto y las obras pueden sufrir deterioros irreparables.

Las exposiciones son y deben ser ante todo un trabajo multidisciplinar en el que el museólogo es una pieza esencial, aunque no todo se ha hecho aún en este sentido.

\section{La mercantilización y la objetivación de resultados}

Las exposiciones temporales pueden ser un gran negocio. Piénsese por ejemplo que una exposición culta de arte sacro titulada Las Edades del Hombre fue visitada en Valladolid por más de un millón de personas en sólo 160 días. La Escuela de Turismo de Valladolid calculó que cerca de 800.000 personas viajaron a esta ciudad justamente para visitarla y que ésta produjo 6.700 millones de pesetas de ingresos totales, directos o inducidos, procedentes de estas visitas en una ciudad que apenas suele registrar cifras altas más que en Semana Santa; o que en dos meses se vendieron 250.000 catálogos de la exposición sobre Velázquez que tuvo lugar en Madrid en 1990. El catálogo forma parte de la estrategia del simulacro por la cual el hombre corriente puede convertirse en consumidor de arte. Sustituye a la colección misma en el contexto de la masificación o "proletarización" del arte, o bien su "democratización" si es que se prefiere una denominación más optimista. Por otra parte, el catálogo ritualiza el contacto con el patrimonio pues constituye el recordatorio y la apropiación material de ese "fragmento" de la colección, esto es, un acto de consumo que queda fijado en la librería doméstica.

La medida del éxito de las exposiciones temporales suele tener que ver más con el número de visitantes que con otras cuestiones como el coste por visitan- te (éste es difícil de encontrar en la literatura especializada) o la eficacia comunicativa (las evaluaciones continúan siendo minoritarias en España). En este sentido, las operaciones expositivas suelen valorarse más por la consecución de efectos propagandísticos y mediáticos que por la concreción de un proceso de transmisión de información, de introducción de la reflexión en el visitante. En este aspecto, la cultura se nos presenta sin tapujos como pantalla publicitaria del poder.

La crítica debería mover a los promotores de exposiciones a ser más eficaces en este sentido. Pero ésta normalmente se agota en la propia obra (en el caso de las exposiciones artísticas) y sólo excepcionalmente alcanza a la museografía en sí. Y aquí debemos subrayar el carácter raquítico que en la "sociedad de la información" tiene el periodismo de investigación, pues las noticias sobre exposiciones temporales suelen ser una copia fiel de la nota de prensa que los promotores entregan a los periodistas en la oportuna rueda de prensa que precede a la inauguración.

Las entidades financieras, más celosas del rendimiento de las inversiones, van a ser las abanderadas en el estudio de público, es decir, en el estudio de las "clientelas", con la intención de evaluar la calidad del servicio que se presta y su efectividad. El sector financiero, muy receptivo a todo aquello que proceda de los Estados Unidos será el primero en promover estudios de público, como los que se habían realizado en los U.S.A. Entre éstos cabe reseñar los realizados por la Fundación Cultural "La Caixa", que encargó a profesionales como Antoni Laporte estudios continuados de público en Barcelona. Actualmente La Caixa d'Estalvis, tras una larga experiencia, acabó comprando la Casa Milá, obra de Gaudí, la popular "Pedrera", constituyendo una gran sala de exposiciones en la planta principal y una exposición interpretativa permanente dedicada a Gaudí en las buhardillas, enlazando con la visita a las terrazas. Hoy por hoy, La Caixa es la primera entidad financiera en Andalucía y su desembarco en las producciones culturales andaluzas es ya un hecho a partir de exposiciones como la dedicada a Los Millares, curiosamente producida de forma absolutamente ajena a los investigadores y a las administraciones implicadas en uno de los procesos de investigación más costosos que se han llevando a cabo en la arqueología andaluza. De momento, el gran espacio de las entidades financieras en su intervención cultural está ocupado por las cajas de ahorro andaluzas (San Fernando, Cajasur o La General). Ésta última, por sólo dar un dato orientativo, en el año 1997 realizó 200 exposiciones en sus diversas salas de la provincia de Granada, algunas de las cuales (la antológica de Sorolla o El Greco. Últimas miradas, del año 200 I), levantan sin duda la envidia de nuestros museos de bellas artes. 